\title{
TESTE DE GERMINAÇÃO DE SEMENTES DE Peltophorum dubium (SPRENGEL) TAUBERT - FABACEAE
}

\author{
Luciana Magda de Oliveira*, Antonio Cláudio Davide**, Maria Laene Moreira de Carvalho*** \\ * Eng ${ }^{\mathrm{a}}$. Florestal, Dr ${ }^{\mathrm{a}}$., Departamento de Engenharia Florestal, UDESC/CAV - luciana@cav.udesc.br \\ **Eng. Agrônomo, Dr., Departamento de Ciências Florestais, UFLA - acdavide@ufla.br \\ ***Eng. Agrônomo, Dr ${ }^{\mathrm{a}}$., Departamento de Agricultura, UFLA - mlaenemc@ufla.br
}

Recebido para publicação: 16/08/2007 - Aceito para publicação: 14/04/2008

\begin{abstract}
Resumo
Para avaliar a influência de diferentes temperaturas e substratos na realização do teste de germinação em sementes de canafístula, foram testadas as temperaturas de $25{ }^{\circ} \mathrm{C}, 20-30{ }^{\circ} \mathrm{C}$ e $30{ }^{\circ} \mathrm{C}$, e os substratos areia (sobre areia) e papel (sobre papel e rolo). O experimento foi realizado em delineamento inteiramente casualizado, em esquema fatorial. Os três lotes utilizados foram colhidos nos municípios de Lavras (MG) e Lins (SP) em diferentes anos de coleta e armazenados em câmara com controle de temperatura e umidade. As sementes foram submetidas a tratamento para quebra da dormência, com imersão em água quente $\left(95^{\circ} \mathrm{C}\right)$ e repouso na mesma água, fora do aquecimento, por 24 horas. A temperatura de $30{ }^{\circ} \mathrm{C}$ e o substrato papel, na forma de rolo, proporcionaram maior porcentagem e velocidade de germinação de sementes de canafístula.

Palavras-chave: Canafístula; análise de sementes.
\end{abstract}

\begin{abstract}
Germination test for Peltophorum dubium (Sprengel) Taubert seeds - Fabaceae. With the perspective of evaluating the influences of different temperatures and substrates for testing the germination of canafistula seeds, temperatures of $25,20 / 30(8 / 16 \mathrm{~h})$ and $30{ }^{\circ} \mathrm{C}$ and substrates on sand, paper and roll were tested. The experiment was produced entirely by tracing the factorial system. The three lots utilized were collected in Lavras (MG) and in Lins (SP). Before the germination tests were installed, the seeds were immersed in hot water $\left(95^{\circ} \mathrm{C}\right)$ and left to rest in the same water, without heat, for 24 hours. The temperature of $30^{\circ} \mathrm{C}$ and substrate of paper roll presented the largest as well as the fastest germination of canafistula seeds.

Keywords: Canafístula; seeds analysis.
\end{abstract}

\section{INTRODUÇÃO}

O teste de germinação é o método mais utilizado para se determinar a qualidade de um lote de sementes e possibilita a avaliação da viabilidade sob condições favoráveis. Nas Regras para Análise de Sementes (BRASIL, 1992) são indicadas as condições ideais de temperatura, substrato, aeração e umidade para várias espécies. As espécies florestais, porém, representam pequena parte do total das espécies listadas. A determinação das condições mais adequadas à realização do teste demanda um volume considerável de pesquisas relacionadas ao ambiente de germinação e à qualidade dos lotes no que se refere à procedência e nível de deterioração.

A canafístula (Peltophorum dubium (Sprengel) Taubert) é uma espécie nativa brasileira de grande importância pela sua utilização como planta ornamental, medicinal, na construção civil e naval e na recuperação de áreas degradadas (CARVALHO, 1994). No entanto, ainda não existem, nas Regras para Análise de Sementes, recomendações para a realização do teste de germinação das espécies brasileiras.

Em trabalhos encontrados na literatura referentes ao teste de germinação de sementes de canafístula, são utilizadas temperaturas que variam de 20 a $30^{\circ} \mathrm{C}$, constantes ou alternadas (AMARAL et al., 1978; BIANCHETTI, 1981; RAMOS; BIANCHETTI, 1984; ALVARENGA; DAVIDE, 1987; 
RAMOS et al., 1995; PEREZ et al., 1998; PEREZ et al., 1999; DONADIO; DEMATTÊ, 2000; PEREZ et al., 2002; MUNIZ et al., 2003; ZHANG et al., 2004; PIROLI et al., 2005). A temperatura em que ocorre a germinação é um fator que tem importante influência sobre o processo, tanto sob o aspecto da germinação total como da velocidade de germinação. A temperatura influencia tanto a velocidade de absorção de água como as reações bioquímicas que determinam todo o processo germinativo (MARCOS FILHO, 2005).

Com relação aos substratos, Alvarenga; Davide (1987) relatam que a germinação de sementes de canafístula pode ser realizada em substratos como o papel, na forma de rolo ou sobre papel, enquanto Bianchetti (1981) recomenda, além desses, os substratos areia e vermiculita. Perez et al. (1999) salientam que o papel-filtro é o mais indicado para o teste de germinação de sementes de canafístula, pela sua praticidade e economia. Os diferentes substratos comumente recomendados variam entre si em sua composição, toxicidade às sementes, associação com patógenos, aeração e capacidade de retenção de umidade, sendo que esses fatores podem favorecer ou prejudicar a germinação das sementes (SCALON et al., 1993).

Objetivou-se com este trabalho avaliar a influência de diferentes temperaturas e substratos na realização do teste de germinação de sementes de canafístula de diferentes lotes.

\section{MATERIAL E MÉTODOS}

Os frutos de canafístula foram colhidos manualmente, em diversas matrizes, nos municípios de Lavras (Lavras 1 e Lavras 2, MG) e Lins (SP). Após a colheita, os frutos foram secos ao sol e mantidos em sacos de aniagem para extração das sementes, realizada com o auxílio de um martelo de borracha. As sementes, que estavam com grau de umidade em torno de $10 \%$, foram armazenadas em sacos de polietileno, em câmara com controle de temperatura e umidade $\left(6-9{ }^{\circ} \mathrm{C} ; 70 \% \mathrm{UR}\right)$. O lote Lavras 1 foi armazenado por 12 meses, e os lotes Lavras 2 e Lins por três meses.

As sementes foram retiradas da câmara de armazenamento e mantidas, por 24 horas, em condições ambientais antes da realização dos testes. O grau de umidade foi determinado pelo método da estufa, a $103 \pm 2{ }^{\circ} \mathrm{C}$ por 17 horas, com sementes quebradas ao meio (BRASIL, 1992). Foram utilizadas quatro repetições de um grama para cada lote e os resultados foram calculados com base no peso das sementes úmidas.

O teste de germinação foi desenvolvido em delineamento inteiramente casualizado em esquema fatorial $3 \times 3 \times 3$, com 4 repetições de 25 sementes. Os tratamentos foram constituídos pela combinação de diferentes substratos (sobre areia-SA, sobre papel-SP e rolo de papel-RP), temperaturas $\left(25^{\circ} \mathrm{C}\right.$ constante, $30{ }^{\circ} \mathrm{C}$ constante e $20 / 30{ }^{\circ} \mathrm{C}(8-16 \mathrm{~h})$ ) e lotes (Lavras 1 , Lavras 2 e Lins). Os substratos foram autoclavados a $120^{\circ} \mathrm{C}$ por 20 minutos e umedecidos com conteúdo de água 2,5 vezes o peso do papel e $200 \mathrm{ml}$ de areia para $100 \mathrm{ml}$ de água destilada em cada gerbox. Os substratos foram reumedecidos quando se apresentavam, visualmente, no início de desidratação. Os testes foram realizados em câmaras de germinação tipo BOD, com luz constante.

Para quebra da dormência, as sementes foram imersas em água quente a $95{ }^{\circ} \mathrm{C}$ e deixadas em repouso na mesma água, fora do aquecimento, por 24 horas a $25{ }^{\circ} \mathrm{C}$ (OLIVEIRA et al., 2003). Antes da instalação do teste de germinação, as sementes foram tratadas com solução de benomyl 0,02\% por 1 minuto.

A avaliação do teste de germinação foi realizada diariamente, e o período de duração do teste foi determinado como sendo o número de dias a partir do qual houve estabilização da germinação. A classificação das plântulas como normais ou anormais foi realizada conforme Alcalay e Amaral (1981), considerando normais as plântulas com todas as estruturas essenciais em perfeito desenvolvimento. Foi calculado o Índice de Velocidade de Germinação (IVG) (MAGUIRE, 1962). O teste de Primeira Contagem foi efetuado no quarto dia após a montagem do teste de germinação.

Os dados de germinação, IVG e Primeira Contagem foram transformados em arc sen. $\sqrt{\mathrm{x}} / 100 \mathrm{e}$ submetidos à análise de variância, e as médias dos tratamentos comparadas pelo teste de Tukey a 5\% de probabilidade, usando o programa SANEST (ZONTA et al., 1985).

\section{RESULTADOS E DISCUSSÃO}

A temperatura e o substrato ideais para a realização do teste de germinação de sementes de canafístula dependem da interação entre esses fatores, além de características do lote a ser avaliado. Para 
os lotes Lavras 1 e Lavras 2, o substrato RP propiciou germinação superior em relação ao substrato SA nas temperaturas de $25^{\circ}$ e $30^{\circ} \mathrm{C}$. Já no substrato $\mathrm{SP}$, foram observados resultados intermediários de germinação em relação aos demais. Na temperatura de $20 / 30{ }^{\circ} \mathrm{C}$ não houve diferença significativa na germinação das sementes semeadas nos diferentes substratos (Tabela 1).

Tabela 1. Resultados do teste de germinação em sementes de Peltophorum dubium, em diferentes substratos e temperaturas.

Table 1. Germination test of Peltophorum dubium seeds, submitted to substrates and temperatures of germination.

\begin{tabular}{|c|c|c|c|c|}
\hline \multirow{2}{*}{ Lote } & \multirow{2}{*}{ Substrato } & \multicolumn{3}{|c|}{ Temperatura $\left({ }^{\circ} \mathrm{C}\right)$} \\
\hline & & 25 & $20 / 30$ & 30 \\
\hline \multirow[t]{3}{*}{ Lavras 1} & RP & $61 \mathrm{~A} \mathrm{a}$ & $63 \mathrm{~A} a$ & $64 \mathrm{~A} \mathrm{a}$ \\
\hline & $\mathrm{SP}$ & $52 \mathrm{AB} a b$ & $72 \mathrm{~A} \mathrm{a}$ & $50 \mathrm{~B} \mathrm{ab}$ \\
\hline & SA & $33 \mathrm{~B} \mathrm{~b}$ & $66 \mathrm{~A} \mathrm{a}$ & $37 \mathrm{~B} \mathrm{~b}$ \\
\hline \multirow[t]{3}{*}{ Lavras 2} & $\mathrm{RP}$ & $64 \mathrm{~A} \mathrm{a}$ & $56 \mathrm{~A} \mathrm{a}$ & $73 \mathrm{~A} \mathrm{a}$ \\
\hline & $\mathrm{SP}$ & $57 \mathrm{~A} \mathrm{ab}$ & $62 \mathrm{~A} \mathrm{a}$ & $68 \mathrm{~A} \mathrm{a}$ \\
\hline & SA & $39 \mathrm{~A} \mathrm{~b}$ & $54 \mathrm{~A} \mathrm{a}$ & $38 \mathrm{~A} \mathrm{~b}$ \\
\hline \multirow[t]{3}{*}{ Lins } & $\mathrm{RP}$ & $82 \mathrm{~B} \mathrm{~b}$ & $67 \mathrm{~B} \mathrm{~b}$ & $97 \mathrm{~A} \mathrm{a}$ \\
\hline & $\mathrm{SP}$ & $98 \mathrm{~A} \mathrm{a}$ & $43 \mathrm{C} \mathrm{c}$ & $84 \mathrm{~B} \mathrm{~b}$ \\
\hline & SA & $96 \mathrm{~A} \mathrm{a}$ & $90 \mathrm{~A} \mathrm{a}$ & $95 \mathrm{~A} \mathrm{ab}$ \\
\hline
\end{tabular}

Médias seguidas pela mesma letra minúscula nas colunas e maiúscula nas linhas não diferem entre si a $5 \%$ de probabilidade.

Quanto ao lote Lins, foi verificado que na temperatura de $25{ }^{\circ} \mathrm{C}$ os melhores resultados de germinação foram obtidos nos substratos SA e SP. Em relação à temperatura de $20 / 30{ }^{\circ} \mathrm{C}$, somente o substrato SA foi eficiente, enquanto que na temperatura de $30^{\circ} \mathrm{C}$, além do substrato SA, o substrato RP permitiu uma maior porcentagem de germinação (Tabela 1).

A temperatura de $20 / 30{ }^{\circ} \mathrm{C}$ no substrato SA e as temperaturas de 25 e $20 / 30{ }^{\circ} \mathrm{C}$ no substrato SP proporcionaram maiores porcentagens de germinação no lote Lavras 1, sem que houvesse diferença significativa entre as temperaturas no substrato RP (Tabela 1).

No lote Lavras 2, não houve diferença significativa entre as temperaturas testadas em todos os substratos. O mesmo foi verificado no lote Lins quando utilizado o substrato SA, enquanto que, com os substratos SP e RP, as maiores porcentagens de germinação foram obtidas nas temperaturas de $25^{\circ} \mathrm{C}$ e 30 ${ }^{\circ} \mathrm{C}$, respectivamente (Tabela 1 ).

A interação observada entre temperatura e substrato na realização do teste de germinação de sementes de canafístula veio corroborar o trabalho realizado por Ramos e Bianchetti (1984), quando constataram que os melhores resultados de germinação foram obtidos com temperatura de $26{ }^{\circ} \mathrm{C}$, em substrato sobre areia, mata-borrão e rolo de papel; na temperatura de $22{ }^{\circ} \mathrm{C}$, em mata-borrão; e na temperatura de $24^{\circ} \mathrm{C}$, em rolo de papel. Já Perez et al. (1999) não observaram diferenças significativas entre os substratos papel, xaxim, algodão e areia, a $27{ }^{\circ} \mathrm{C}$, no entanto os autores indicam o substrato papel, pela praticidade e economia.

Além da porcentagem final de germinação, os resultados de velocidade e uniformidade de germinação também são fundamentais na escolha de substrato e temperatura adequados para determinada espécie. Para o lote Lavras 1 , os tratamentos $25^{\circ} \mathrm{C} / \mathrm{RP}, 20-30{ }^{\circ} \mathrm{C} / \mathrm{SA}$ e $30^{\circ} \mathrm{C} / \mathrm{RP}$ propiciaram resultados finais de germinação superiores e estatisticamente iguais, e permitiram, ainda, que esses resultados fossem alcançados no $8^{\mathrm{o}}$ dia após a montagem do teste. Isso não foi verificado nos demais tratamentos, que apresentaram resultados finais de germinação semelhantes, como o tratamento $20-30{ }^{\circ} \mathrm{C} / \mathrm{SP}$ (Figura 1).

Para o lote Lavras 2, os tratamentos $30^{\circ} \mathrm{C} / \mathrm{SP}$ e $30^{\circ} \mathrm{C} / \mathrm{RP}$ foram os mais eficientes na promoção da germinação e possibilitaram que os resultados finais fossem obtidos em menor tempo, no $8^{\circ}$ dia após a montagem do teste, semelhante ao lote Lavras 1 (Figura 2).

No lote Lins foi observado que os tratamentos $25{ }^{\circ} \mathrm{C} / \mathrm{SA}, 20-30{ }^{\circ} \mathrm{C} / \mathrm{SA}, 30{ }^{\circ} \mathrm{C} / \mathrm{SA}$ e $30{ }^{\circ} \mathrm{C} / \mathrm{RP}$ permitiram que a última contagem do teste de germinação fosse realizada no $10^{\circ}$ dia após a montagem do teste, enquanto que o tratamento $25^{\circ} \mathrm{C} / \mathrm{SP}$ possibilitou o máximo de germinação somente no $18^{\circ}$ dia após a montagem do teste (Figura 3). 


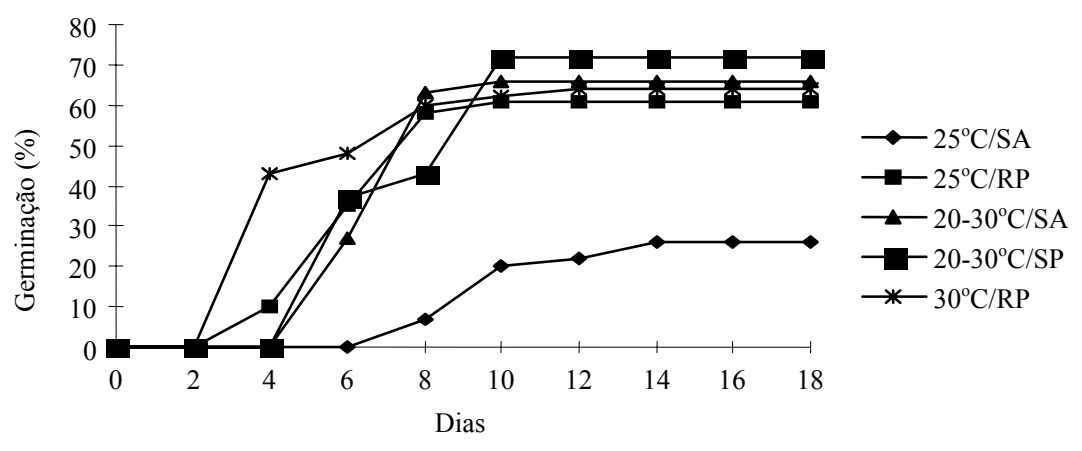

Figura 1. Germinação acumulada de sementes de Peltophorum dubium do lote Lavras 1, submetidas a diferentes substratos e temperaturas.

Figure 1. Accumulated germination of Peltophorum dubium seeds (lot Lavras 1), submitted to substrates and temperatures of germination.

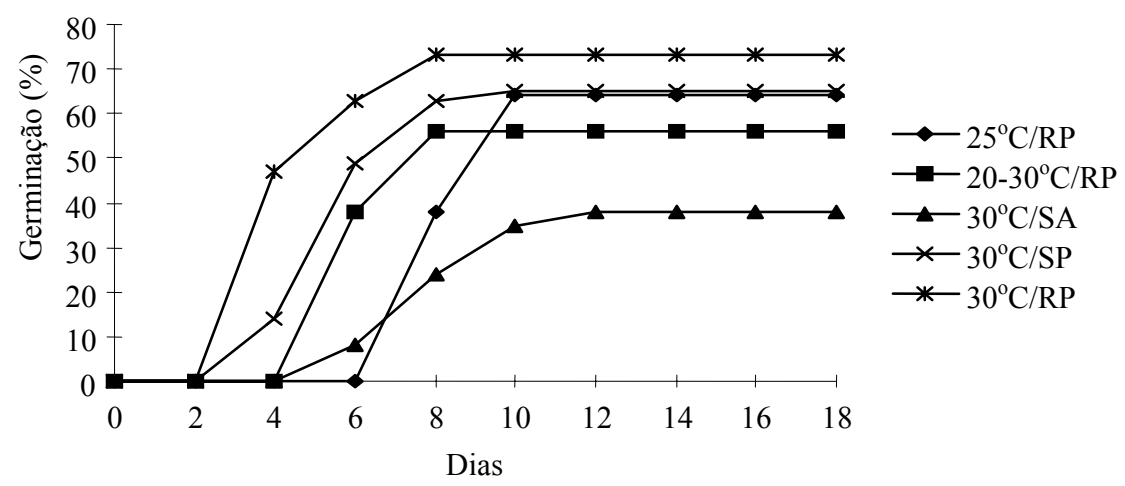

Figura 2. Germinação acumulada de sementes de Peltophorum dubium do lote Lavras 2, submetidas a diferentes substratos e temperaturas.

Figure 2. Accumulated germination of Peltophorum dubium seeds (lot Lavras 2), submitted to substrates and temperatures of germination.

$\mathrm{O}$ tratamento $30{ }^{\circ} \mathrm{C} / \mathrm{RP}$ foi, dos métodos eficientes na promoção da germinação em menor período de tempo, o único selecionado nos três lotes utilizados. Além disso, a superioridade desse tratamento, em relação aos demais, com germinação final significativamente igual, foi verificada pelos resultados obtidos nos testes de primeira contagem e índice de velocidade de germinação (Tabelas 2 e 3 ). Esse resultado está de acordo com os obtidos por Alvarenga e Davide (1987) em sementes dessa espécie.

A eficiência da temperatura de $30^{\circ} \mathrm{C}$ na promoção da germinação de sementes de canafístula é relatada por vários autores, contudo, os substratos utilizados variam, como areia (BIANCHETTI, 1981; RAMOS e BIANCHETTI, 1984), vermiculita e sobre papel (BIANCHETTI, 1981). Borges e Rena (1993) relatam que a faixa de 20 a $30{ }^{\circ} \mathrm{C}$ é a mais adequada para a germinação de grande número de espécies florestais subtropicais e tropicais. Perez et al. (1998) salientam que a temperatura ótima de germinação de sementes de canafistula situa-se entre $27-30{ }^{\circ} \mathrm{C}$. 


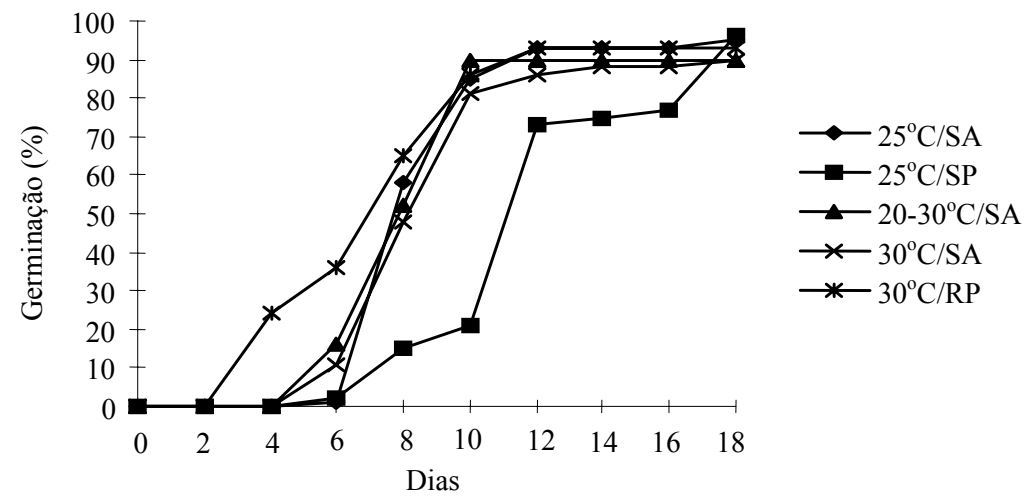

Figura 3. Germinação acumulada de sementes de Peltophorum dubium do lote Lins, submetidas a diferentes substratos e temperaturas.

Figure 3. Accumulated germination of Peltophorum dubium seeds (lot Lins), submitted to substrates and temperatures of germination.

Tabela 2. Primeira contagem do teste de germinação de sementes de Peltophorum dubium.

Table 2. First count of germination test of Peltophorum dubium seeds.

\begin{tabular}{lcccc}
\hline \multirow{2}{*}{ Lotes } & Substrato & \multicolumn{3}{c}{ Temperatura $\left(\mathbf{~}^{\mathbf{O}} \mathbf{C}\right)$} \\
\cline { 2 - 5 } & & $\mathbf{2 5}$ & $\mathbf{2 0} / \mathbf{3 0}$ & $\mathbf{3 0}$ \\
\hline Lavras 1 & SA & 0 & 0 & 0 \\
& SP & 0 & 0 & 18 \\
\multirow{2}{*}{ Lavras 2 } & RP & 3 & 0 & 43 \\
& SA & 0 & 0 & 0 \\
\multirow{2}{*}{ Lins } & SP & 0 & 0 & 14 \\
& RP & 0 & 0 & 24 \\
& SA & 0 & 0 & 0 \\
& SP & 2 & 0 & 47 \\
\hline
\end{tabular}

Tabela 3. Índice de velocidade de germinação de sementes de Peltophorum dubium.

Table 3. Speed of germination of Peltophorum dubium seeds.

\begin{tabular}{lcccc}
\hline \multirow{2}{*}{ Lotes } & Substrato & \multicolumn{3}{c}{ Temperatura $\left({ }^{\mathbf{0}} \mathbf{C}\right)$} \\
\cline { 2 - 4 } & & $\mathbf{2 5}$ & $\mathbf{2 0} / \mathbf{3 0}$ & $\mathbf{3 0}$ \\
\hline Lavras 1 & $\mathrm{SA}$ & $0.98 \mathrm{~B} \mathrm{~b}$ & $2.71 \mathrm{~A} \mathrm{a}$ & $1.50 \mathrm{~B} \mathrm{~b}$ \\
& $\mathrm{SP}$ & $2.08 \mathrm{~A} \mathrm{a}$ & $2.24 \mathrm{~A} \mathrm{a}$ & $2.63 \mathrm{~A} \mathrm{a}$ \\
Lavras 2 & $\mathrm{RP}$ & $2.90 \mathrm{~B} \mathrm{a}$ & $2.55 \mathrm{AB} \mathrm{a}$ & $3.33 \mathrm{~A} \mathrm{a}$ \\
& $\mathrm{SA}$ & $2.42 \mathrm{~A} \mathrm{a}$ & $2.97 \mathrm{~A} \mathrm{a}$ & $3.21 \mathrm{~A} \mathrm{a}$ \\
Lins & $\mathrm{SP}$ & $2.77 \mathrm{~A} \mathrm{a}$ & $1.32 \mathrm{~B} \mathrm{~b}$ & $3.08 \mathrm{~A} \mathrm{a}$ \\
& $\mathrm{RP}$ & $2.14 \mathrm{~B} \mathrm{a}$ & $2.52 \mathrm{AB} \mathrm{a}$ & $3.40 \mathrm{~A} \mathrm{a}$ \\
& $\mathrm{SA}$ & $2.94 \mathrm{~B} \mathrm{~b}$ & $1.23 \mathrm{~A} \mathrm{a}$ & $3.12 \mathrm{~B} \mathrm{~b}$ \\
& $\mathrm{SP}$ & $2.28 \mathrm{AB} \mathrm{a}$ & $1.92 \mathrm{~B} \mathrm{a}$ & $6.46 \mathrm{~A} \mathrm{a}$ \\
\hline
\end{tabular}

Médias seguidas pela mesma letra minúscula nas colunas e maiúscula nas linhas não diferem entre si pelo teste de Tukey a $5 \%$ de probabilidade.

Como observado neste trabalho, o substrato papel na forma de rolo confere uma série de vantagens, tais como o melhor desenvolvimento das estruturas essenciais das plântulas, permitindo, dessa forma, maior rapidez e segurança na avaliação, maior espaçamento entre as plântulas (evitando contaminações e reduzindo a incidência de microrganismos no substrato), maior facilidade na avaliação 
do teste, além de ocupar menos espaço no germinador, possibilitando a execução de um maior número de análises simultaneamente (LIMA e GARCIA, 1996). No entanto, apesar do substrato RP permitir um contato maior com as sementes em relação aos substratos SA e SP, facilitando, dessa maneira, a embebição e posterior germinação, esse substrato teve que ser umedecido diariamente, devido à rápida desidratação observada, fato verificado também por Macedo (1985) em sementes de Hevea brasiliensis Müll. Arg. O umedecimento do substrato RP pode ser feito sem a necessidade de se desfazer o rolo, não favorecendo, dessa maneira, uma possível contaminação.

A duração do teste de germinação de sementes de canafístula a $30^{\circ} \mathrm{C}$ em rolo de papel pode ser de dez dias, sendo que a primeira contagem pode ser realizada no $4^{\circ}$ dia após a instalação do teste. A duração do teste de germinação de sementes de canafístula, nos trabalhos encontrados na literatura, varia de acordo com o método de quebra de dormência e com a temperatura e substrato utilizados. Os resultados alcançados neste trabalho estão de acordo com os obtidos por Salerno et al. (1996), que obtiveram resultados de germinação em um período médio de dez dias, com a imersão das sementes em água quente por 18 horas e instalação do teste de germinação em papel na forma de rolo e temperatura de $30{ }^{\circ} \mathrm{C}$.

\section{CONCLUSÃO}

A temperatura de $30^{\circ} \mathrm{C}$ e o substrato papel, na forma de rolo, proporcionaram condições ideais de germinação para sementes de canafístula. Nessa condição é alcançada a maior velocidade de germinação.

\section{REFERÊNCIAS}

ALCALAY, N.; AMARAL, D. M. I. Descrição de plântulas de algumas essências florestais de interesse econômico para o Rio Grande do Sul. Roessléria, Porto Alegre, v. 4, n. 1, p. 85-100, 1981.

ALVARENGA, S.; DAVIDE, A. C. Influência da temperatura e do substrato na germinação de sementes de três essências florestais. In: CONGRESSO BRASILEIRO DE SEMENTES, 5., 1987, Gramado. Anais do ... Brasília, DF: ABRATES, 1987. p.149.

AMARAL, D. M. I.; GALLARDO, V. R. R.; SALTZ, N. A.; JAMARDO, A. Metodização e tratamento pré-germinativo de sementes florestais. Roessléria, Porto Alegre, v. 1, n. 2, p. 40-56, 1978.

BIANCHETTI, A. Produção e tecnologia de sementes de essências florestais. In: SEMINÁRIO DE SEMENTES E VIVEIRO FLORESTAIS, 1., 1981, Curitiba. Anais do ... Curitiba: FUPEF, 1981. p.1542.

BRASIL. Ministério da Agricultura. Regras para Análise de Sementes. Brasília, DF, 1992. 365 p.

DONADIO, N. M. M.; DEMATTÊ, M. E. S. P. Morfologia de frutos, sementes e plântulas de canafístula (Peltophorum dubium (Spreng.) Taub.) e jacarandá-da-bahia (Dalbergia nigra (Vell.) Fr. All. ex Benth.) - Fabaceae. Revista Brasileira de Sementes, Brasília, DF, v. 22, n. 1, p. 64-73, 2000.

LIMA, D.; GARCIA, L. C. Avaliação de métodos para o teste de germinação em sementes de Acacia mangium Willd. Revista Brasileira de Sementes, Brasília, DF, v. 18, n. 2, p. 180-185, 1996.

MACEDO, R. L. G. Influência da temperatura, substrato e luminosidade na germinação e avaliação da qualidade fisiológica das sementes de seringueira - (Hevea brasiliensis Muell Arg.). 77 p. Dissertação (Mestrado) - ESALQ, Lavras, 1985.

MAGUIRE, J. D. Speed of germination-aid in selection and evaluation for seedling emergence and vigor. Crop Science, Madison, v. 2, n. 1, p. 176-177, jan./feb. 1962.

MUNIZ, M. F. B.; KAUFFMANN, M.; DISARZ, R.; SIGNO, P.; NETTO, C. C. Germinação de sementes de canafistula (Peltophorum dubium (Sprengel) Taubert). In: CONGRESSO BRASILEIRO DE SEMENTES, 13., 2003, Gramado. Anais do ... Gramado : ABRATES, 2003. p. 363. 
OLIVEIRA, E. C.; PINÃ-RODRIGUES, F. C. M.; FIGLIOLIA, M. B. Propostas para a padronização de metodologias em análise de sementes florestais. Revista Brasileira de Sementes, Brasília, DF, n. 1/3, p. $1-42,1989$.

OLIVEIRA, L. M.; DAVIDE, A. C.; CARVALHO, M. L. M. Avaliação de métodos para a quebra da dormência e para a desinfestação de sementes de canafístula (Peltophorum dubium (Sprengel) Taubert). Revista Árvore, Viçosa, MG, v. 27, n. 5, p. 597-603, 2003.

PEREZ, S. C. J. G. A.; FANTI, S. C.; CASALI, C. A. Influência do armazenamento, substrato, envelhecimento precoce e profundidade de semeadura na germinação de canafistula. Bragantia, Campinas, v. 58, n. 1, p. 57-68, 1999.

PEREZ, S. C. J. G. A.; FANTI, S. C.; CASALI, C. A. Limites de temperatura e estresse térmico na germinação de sementes de Peltophorum dubium (Spreng) Taubert. Revista Brasileira de Sementes, Brasília, DF, v. 20, n. 1, p. 134-142, 1998.

PEREZ, S. C. J. G. A.; FANTI, S. C.; CASALI, C. A. Germinação de sementes de canafistula (Peltophorum dubium (Spreng.) Taubert) em resposta ao estresse salino na ausência e presença de luz. Cientifica, Jaboticabal, v. 30, n. 1/2, p. 89-102, 2002.

PIROLI, E. L.; CUSTÓDIO, C. C.; ROCHA, M. R. V.; UDENAL, J. L. Germinação de sementes de canafístula Peltophorum dubium (Spreng.) Taub. tratadas para superação da dormência. Colloquium Agrariae, Presidente Prudente, v. 1, n. 1, p. 13-18, 2005.

RAMOS, A.; BIANCHETTI, A. Influência da temperatura e substrato na germinação de sementes florestais. In: SIMPÓSIO INTERNACIONAL - MÉTODOS DE PRODUÇÃO DE QUALIDADE DE SEMENTES E MUDAS FLORESTAIS, 1984, Curitiba. Anais do ... Curitiba: UFPR, 1984. p. 193-204.

RAMOS, A.; BIANChetTi, A.; MARTINS, E. G.; FOWLER, J. A. P.; AlVES, V. F. Substratos e temperaturas para a germinação de sementes de canafístula (Peltophorum dubium). Colombo: EMBRAPA Florestas, 1995. (Comunicado Técnico, n. 5).

SALERNO, A. R.; SHALLENBERGER, T. C. H.; STUKER, H. Quebra de dormência em sementes de canafístula. Agropecuária Catarinense, Florianópolis, v. 9, n. 1, p. 9-11, mar. 1996.

SCALON, S. P. Q.; ALVARENGA, A. A.; DAVIDE, A. C. Influência do substrato, temperatura, umidade e armazenamento sobre a germinação de sementes de pau-pereira (Platycyamus regnellii Benth.). Revista Brasileira de Sementes, Brasília, DF, v. 15, n. 1, p. 143-146. 1993.

ZHANG, W. L.; LI, L. H.; ZU, Y. G.; PEREZ, S. Effect of priming on the germination of Peltophorum dubium seeds under water stress. Journal of Forestry Research, Japão, v. 15, n. 4, p. 287-290, 2004.

ZONTA, E. F.; MACHADO, A. A.; SILVEIRA JUNIOR, P. Sistema de análise estatística (SANEST) para microcomputador (versão 1.00$)$. In: SIMPÓSIO DE ESTATÍSTICA APLICADA À EXPERIMENTAÇÃO AGRONÔMICA, 1., 1985, Piracicaba. [Anais...]. Piracicaba: ESALQ/USP, 1985. p. 74-90. 